\title{
Does BCG vaccine prevent contract and severity of COVID-19 infection in India? A situational analysis
}

Bijaya Nanda Naik ${ }^{1}$, Sanjay Pandey ${ }^{2}$, Chandra Mani Singh ${ }^{3}$, Alok Ranjan ${ }^{4}$, Manisha Verma ${ }^{5}$, Ebbie Thomas ${ }^{6}$

${ }^{1}$ Assistant Professor, Department of Community and Family Medicine, All India Institute of Medical Sciences, Patna, Phulwarisharif, Bihar, India; ${ }^{2}$ Additional Professor, Department of Community and Family Medicine, All India Institute of Medical Sciences, Patna, Phulwarisharif, Bihar, India; ${ }^{3}$ Professor \& Head, Department of Community and Family Medicine, All India Institute of Medical Sciences, Patna, Phulwarisharif, Bihar, India; ${ }^{4}$ Assistant Professor, Department of Community and Family Medicine, All India Institute of Medical Sciences, Patna, Phulwarisharif, Bihar, India; ${ }^{5}$ Senior Resident Department of Community and Family Medicine, All India Institute of Medical Sciences, Patna, Phulwarisharif, Bihar, India; ${ }^{6}$ Tutor, Department of Community Medicine, Namo Medical College, Silvassa, Dadra Nagar Haveli.

\begin{tabular}{|c|c|c|c|c|c|c|c|c|}
\hline Abstract & Introduction & Methodology & Results & Conclusion & References & Citation & \multicolumn{2}{|c|}{ Tables / Figures } \\
\hline \multicolumn{9}{|c|}{ ing Author } \\
\hline \multicolumn{8}{|c|}{$\begin{array}{l}\text { Dr Sanjay Pandey, Additional Professor, Department of Community and Family Medicine, All India Institute } \\
\text { of Medical Sciences(AllMS), Patna, Phulwarisharif-801505, Bihar, India. } \\
\text { E Mail ID: drsanjayp69@gmail.com }\end{array}$} & 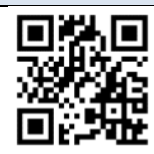 \\
\hline
\end{tabular}

\section{Citation}

Naik BN, Pandey S, Singh CM, Ranjan A, verma M, Thomas E. Does BCG vaccine prevent contract and severity of COVID-19 infection in India? A situational analysis Indian J Comm Health. 2021;33(2):304-308. https://doi.org/10.47203/IJCH.2021.v33i02.014

Source of Funding: Nil Conflict of Interest: None declared

Article Cycle

Received: 16/11/2020; Revision: 05/04/2021; Accepted: 12/05/2021; Published: 30/06/2021

This work is licensed under a Creative Commons Attribution 4.0 International License.

\section{Abstract}

Background: The COVID-19 pandemic has created worldwide emergency with morbidities, mortality and panic. The BCG vaccine, usually given to prevent childhood tuberculosis, surfaced as an option as suggested by some ecological observations. However, some others studies could not establish and explain the protective effects of BCG vaccination against COVID-19 pandemic. India is one country with high BCG vaccination coverage and is among the countries with lowest COVID-19 case fatality rate. Aims and Objectives: We examine the relationship between the BCG coverage and COVID-19 burden in various states/UTs of India. Materials and methods: The information on BCG coverage and morbidity and mortality of COVID-19 was obtained from NFHS and www.covid19India.org respectively. Results: The analysis suggested very weak positive relationship of BCG coverage with cases and deaths due to COVID-19. Moderate positive relationship was observed between BCG coverage and COVID-19 case fatality rate even after adjusting for health system performance. Conclusion: The conclusion of the study is against the role of BCG vaccination in containing the COVID-19 pandemic. The positive correlation which is not significant may be spurious and affected by many confounding factors like co-morbid conditions, testing strategies, population level immunity for other viral infections etc. Hence, the states and UTs should not be complacent by the hypothesized role of BCG vaccine in COVID-19 control. Rather, they should continue with the principles of social distancing, contact tracing, treating and surveillance of COVID-19.

\section{Keywords}

COVID-19; SARS Cov-2; Pandemics; BCG Vaccine; Delivery of Health Care

\section{Introduction}

The Coronavirus disease (COVID-19) is an infectious disease caused by the novel corona virus named as SARSCoV-2. The COVID-19 pandemic originated in the city of Wuhan; the capital of Hubei province of China in December 2019 has emerged as the major public health crisis in 2020(1). The pandemic has spread to more than 200 countries with US followed by India and Bazil the worst affected countries. As of October 2020, SARS-CoV-2 has infected 40,661,005 patients, with 1,123,180 deaths across 215 countries. India has also reported 76,49,102 COVID-19 cases and 1,19, 536 deaths during the same time period. Though majority of the individuals infected with SARS CoV-2 are asymptomatic, a low but significant proportion of infected persons have developed severe disease leading to death(2). 
The impact of COVID-19 varied across countries around the globe. The empirical data has shown that some of the developed countries have reported high number of cases per million population and high care fatality rate despite imposing high-level mitigation strategies and stringent containment measures. Hence, the researchers around the world have reviewed the role of cultural norms, health infrastructure and health policies of different countries to identify the possible factors making difference in infections rate and death rate across the countries. Few ecological studies have suggested the possible role of BCG vaccination in protecting against the COVID-19(3-9). National immunization policy in some countries (Japan, South Korea, India and few others) has mandatory BCG vaccination while in several other countries (Italy, US and other developed countries) it has not(10). However, there is no consistent findings across studies reporting the possible role of BCG vaccination in protecting against the COVID-19. Few ecological studies have reported lower COVID-19 morbidity and mortality in countries with mandatory BCG vaccination during childhood compared to other countries which don't $(6,11,12)$. However, few other studies could not establish such findings $(13,14)$.

India has got very low mortality from COVID-19 as compared to western countries(15). According to MoHFW, Gol the COVID-19 CFR in India is 1.49 at the end of October 2020. India has universal BCG vaccination policy for infants. However, the CFR varied across the states and union territories (UTs) in India.

\section{Aim \& Objective}

To study the relationship between the BCG coverage and severity of COVID-19 across states and UTs in India.

\section{Material \& Methods}

This explorative ecological observational study was carried during the month of October, 2020. We collected the state and UT wise BCG coverage information from the National Family Health Survey (NFHS) - 2, NFHS-3 and NFHS-4 reports(16). The information on cumulative COVID-19 cases and deaths was obtained from www.covid19India.org. The information was collected on October 23, 2020. Health infrastructure and health system performance can influence the BCG vaccination coverage as well as the COVID-19 infections and deaths. Infant mortality rate is considered as the proxy indicator for health infrastructure and health system performance(17). The information on IMR was collected from the Sample Registration System (SRS) March 2020 report(18).

The information collected was entered in Microsoft Excel and statistical analysis was performed using SPSS version 20. The number of COVID-19 deaths and CFR were taken as proxy for severity of COVID-19. The case fatality rate was calculated by the following formula

$\mathrm{CFR}=\left(\frac{\text { total number of COVID-19 deaths }}{\text { total number of COVID-19 infections }}\right) * 100$
Person correlation was performed to assess the correlation between BCG vaccination coverage and severity of COVID-19. The confounding effect of health infrastructure and health system performance (IMR) was nullified by performing partial Pearson correlation analysis. The correlation category [negligible or low, $r$ $<0.5$; moderate, $r=0.5-0.7$; high, $r>0.7$ ] was used to report the correlation between BCG vaccination coverage and severity of COVID-19 in India(19). A p value of $<0.05$ was considered statistically significant.

The information was collected from reports and website available in public domain and involved statistical analysis of secondary data. Hence, permission from ethics committee is not required.

\section{Results}

The [Table 1] shows the information on COVID-19 status in India as on 22nd October 2020. Maharashtra reported the highest number of cases $(16,25,179)$ and deaths (42831) due to COVID-19. Mizoram reported the lowest number of cases (2359) and deaths (0) due to COVID-19. The CFR in India was calculated to be $1.51 \%$ as on $22 \mathrm{nd}$ October 2020. The median CFR was calculated to be $1.24 \%$ (Range: 0 to 3.14). Mizoram was found to have zero CFR as no death due to COVID-19 was reported as of 22nd October 2020. Punjab was found to have highest CFR (3.14\%) followed by Maharashtra (2.64\%) related COVID19. The BCG vaccination coverage in India was recorded to be $91.9 \%$ (NFHS-4), 88\% (NFHS-3) and $88.7 \%$ (NFHS-2). The highest BCG vaccination coverage was recorded by Goa (99.2\%), Tamil Nadu (99.5\%) and Goa (100\%) during NFHS2, NFHS-3 and NFHS-4 survey respectively. The lowest BCG vaccination coverage was recorded by Bihar (37.7\%), Nagaland (46.30\%) and Nagaland (68.10\%) during NFHS2, NFHS-3 and NFHS-4 survey respectively. The IMR in India is 32 per 1000 livebirths (SRS 2020). The highest (48) and lowest (4) IMR was reported from Madhya Pradesh and Nagaland respectively.

[Table 2] shows the correlation and partial correlation of BCG vaccination coverage with number of COVID-19 related cases, deaths and CFR. BCG coverage was not found to be correlated with COVID-19 related cases and deaths even after controlling the influence of status of health care delivery system (proxy given by IMR). However, BCG coverage was found to have low and positive correlation with COVID-19 CFR even after controlling the influence of status of health care delivery system $(r=0.458, p$ value $=0.008)$. The correlation of BCG coverage and COVID-19 CFR was found to be statistically significant. The positive correlation of BCG coverage and COVID-19 CFR is also depicted in [Figure 1] (NFHS-3) and [Figure 2] (NFHS-2).

\section{Discussion}

BCG vaccination is given to prevent childhood tuberculosis. Apart from giving protection against tuberculosis, the BCG is also implicated in providing non- 
specific effects on various other infections especially the respiratory pathogens(20). However, the non-specific effects were not long lasting and protects for about 5-10 years till adulthood (21). The role of BCG vaccination in reducing burden of COVID-19 is still mystifying. Contrasting evidences have been reported by different studies on role of BCG vaccination coverage in reducing burden of COVID-19 in India.

Similar to our study, a study from Israel has reported no role of BCG in reducing burden of COVID-19. The study had analysed the development of COVID-19 among Israeli population borne during 1980s whose BCG vaccinations status was known(13). Similarly, Meena et al from India also could not establish the correlation between BCG vaccination coverage and COVID-19 burden across the countries in the world(14). A systematic review of all the published literature also could not find any solid evidence to recommend BCG vaccination for protection against COVID-19(22).

Our study failed to support the role of BCG vaccination (coverage) in reducing the burden of COVID-19. However, several ecological studies have reported the protective nature of BCG vaccination against COVID-19. Jain et al have attributed low COVID-19 burden in South Asian countries to mandatory BCG vaccination policy(15). Ebina et al reported the protective role of universal childhood BCG vaccination policy in low COVID-19 mortality(23). Madan et al have reported that Higher TB incidence and BCG coverage were found to be associated with lesser incidence of COVID-19 and recommended further research into pathogenesis and immune response in COVID-19(24). However, most of the studies were observational and had not taken into consideration ecological differences, prevalence of co-morbid conditions, age structure of population and testing strategies.

The finding of studies reporting protective role of BCG vaccination policy could be coincidental. Many of the studies have analysed the presence or absence of mandatory BCG vaccination policy(25). Many of the countries with mandatory BCG vaccination policy have BCG coverage of $10-15 \%$. These studies might have missed the confounding effects of factors like testing strategy, travel restrictions etc. This raises the validity of such finding and points towards alternative explanation(21).

Our analysis showed that states and UTs with better BCG coverage have high COVID-19 CFR. This is against the widescale report of role of BCG vaccination in reducing the COVID-19 burden. This could be spurious and there could be other plausible explanations for high COVID-19 burden in states and UTs with BCG vaccination coverage in India.

\section{Conclusion}

This study shows no inverse correlation between BCG coverage and COVID-19 burden in India. The earlier studies on cross country comparison showing protective effect of BCG against COVID-19 may be spurious. Further research using randomized control design is needed to substantiated the facts. Till then, health system and the authority should not get complacent on management of COVID-19 pandemic and promote the practice of hygiene, social distancing, contract tracing, treating and surveillance of COVID-19 in India.

\section{Recommendation}

The states and UTs should not be complacent by the earlier hypothesized role of BCG vaccine in COVID-19 control. Rather, they should continue with the principles of social distancing, contact tracing, treating and surveillance of COVID-19.

\section{Limitation of the study}

The age wise information of the COVID-19 affected population is not available in any public domain. Though, BCG vaccination was stated along with universal immunization programme during 1970s, the state/UT wise vaccination coverage is available earliest in NFHS-2 report (1998-99). Hence, it was not possible to include the age specific COVID-19 affected population to correlate with BCG vaccination coverage in India. Since this is an ecological study the ecological fallacy cannot be rule out.

\section{Relevance of the study}

This study adds to the body of the evidence that BCG vaccination status has no role in prevention of COVID-19 in adults.

\section{Authors Contribution}

All authors contributed equally.

\section{References}

1. Mackenzie JS, Smith DW. COVID-19: a novel zoonotic disease caused by a coronavirus from China: what we know and what we don't. Microbiol Aust 2020: MA20013. doi: 10.1071/MA20013

2. Oran DP, Topol EJ. Prevalence of Asymptomatic SARS-CoV-2 Infection. Ann Intern Med 2020: M20-3012. Published online 2020 Jun 3. doi: 10.7326/M20-3012

3. Cirovic B, de Bree LCJ, Groh L, Blok BA, Chan J, van der Velden WJFM, et al. BCG Vaccination in Humans Elicits Trained Immunity via the Hematopoietic Progenitor Compartment. Cell Host Microbe. 2020 12;28(2):322-334.e5.

4. Curtis N, Sparrow A, Ghebreyesus TA, Netea MG. Considering BCG vaccination to reduce the impact of COVID-19. Lancet Lond Engl. 2020 16;395(10236):1545-6.

5. O'Neill LAJ, Netea MG. BCG-induced trained immunity: can it offer protection against COVID-19? Nat Rev Immunol. 2020;20(6):3357.

6. Miller A, Reandelar MJ, Fasciglione K, Roumenova V, Li Y, Otazu GH. Correlation between universal BCG vaccination policy and reduced mortality for COVID-19. medRxiv. 2020 Sep 14;2020.03.24.20042937.

7. Athikarisamy SE, Jacob JR. Does BCG bolster one's immunity against COVID-19? Rapid response in theBMJ 2020. Available from: https://www.bmj.com/content/368/bmj.m1252/rr-4 $\quad$ (Last accessed on 25.06.2021)

8. Hegarty P, Kamat A, Zafirakis H, Dinardo A. BCG vaccination may be protective against Covid-19. 2020. Available from: http://onrrussia.ru/sites/default/files/bcgversuscovid-19.pdf (last accessed on 25.03.2021) 
INDIAN JOURNAL OF COMMUNITY HEALTH / VOL 33 / ISSUE NO 02 / APR- JUN 2021

9. Gursel M, Gursel I. Is Global BCG Vaccination Coverage Relevant to The Progression Of SARS-CoV-2 Pandemic? Med Hypotheses 2020: 109707. doi: 10.1016/j.mehy.2020.109707

10. Zwerling A, Behr MA, Verma A, Brewer TF, Menzies D, Pai M. The BCG World Atlas: A Database of Global BCG Vaccination Policies and Practices. PLoS Med 2011;8(3): e1001012. doi: 10.1371/journal.pmed.1001012

11. Mohapatra PR, Mishra B, Behera B. BCG vaccination induced protection from COVID-19. Indian J Tuberc. 2021;68(1):119-124. doi: 10.1016/j.ijtb.2020.08.004

12. Berg MK, Yu Q, Salvador CE, Melani I, Kitayama S. Mandated Bacillus Calmette-Guérin (BCG) vaccination predicts flattened curves for the spread of COVID-19. Sci Adv. 2020;6(32):eabc1463. doi: 10.1126/sciadv.abc1463. PMID: 32923613; PMCID: PMC7457335.

13. Hamiel U, Kozer E, Youngster I. SARS-CoV-2 Rates in BCGVaccinated and Unvaccinated Young Adults. JAMA 2020;323(22):2340-1.

14. Meena, J., Yadav, A. \& Kumar, J. BCG Vaccination Policy and Protection Against COVID-19. Indian J Pediatr 87, 749 (2020). https://doi.org/10.1007/s12098-020-03371-3

15. Jain VK, lyengar K, Vaish A, Vaishya R. Differential mortality in COVID-19 patients from India and western countries. Diabetes Metab Syndr. 2020 Oct;14(5):1037-41.

16. National Family Health Survey. Available from: http://rchiips.org/nfhs/nfhs2.shtml (Last accessed on 25.06.2021)

17. Leatherman S. Performance measurement for health system improvement: Experiences, challenges and prospects [Internet]. Smith PC, Mossialos E, Papanicolas I, editors. Cambridge:
[BCG vaccine...] | Naik BN et a Cambridge University Press; 2010. Available from: http://ebooks.cambridge.org/ref/id/CBO9780511711800 (Last accessed on 25.06.2021)

18. Sample Registration Systems (SRS) Bulletin, May 2020. Office of the Registrar General of India, Gol. Available from: https://censusindia.gov.in/vital statistics/SRS Bulletins/SRS\%20B ulletin 2018.pdf (Last accessed on 25.06.2021)

19. Mukaka M. A guide to appropriate use of Correlation coefficient in medical research. Malawi Med J J Med Assoc Malawi. 2012 Sep;24(3):69-71.

20. Moorlag SJCFM, Arts RJW, van Crevel R, Netea MG. Non-specific effects of BCG vaccine on viral infections. Clin Microbiol Infect Off Publ Eur Soc Clin Microbiol Infect Dis. 2019;25(12):1473-8.

21. Kumar J, Meena J. Demystifying BCG Vaccine and COVID-19 Relationship. Indian Pediatr. 2020;57(6):588-9.

22. Riccò M, Gualerzi G, Ranzieri S, Bragazzi NL. Stop playing with data: there is no sound evidence that Bacille Calmette-Guérin may avoid SARS-CoV-2 infection (for now). Acta Bio Medica Atenei Parm. 2020;91(2):207-13.

23. Ebina-Shibuya R, Horita N, Namkoong H, Kaneko T. National policies for paediatric universal BCG vaccination were associated with decreased mortality due to COVID-19. Respirol Carlton Vic. 2020;25(8):898-9.

24. Madan M, Pahuja S, Mohan A, Pandey RM, Madan K, Hadda V, et al. TB infection and BCG vaccination: are we protected from COVID19? Public Health. 2020;185:91-2.

25. Roy S. Does the Bacillus Calmette-Guérin vaccine provide protection from COVID-19? Indian J Med Sci. 2020;72(1):17-20.

\section{Tables}

TABLE 1 CORRELATION AND PARTIAL CORRELATION OF BCG COVERAGE WITH COVID-19 RELATED CASES, DEATHS AND CFR IN INDIA

\begin{tabular}{|c|c|c|c|c|c|c|c|}
\hline State/UT & $\begin{array}{c}\text { Case_22 } \\
20\end{array}$ & $\begin{array}{l}\text { Death_2 } \\
2 \_20\end{array}$ & $\begin{array}{c}\text { BCG } \\
\text { coverage_NFHS2 }\end{array}$ & $\begin{array}{c}\text { BCG } \\
\text { coverage_NFHS3 }\end{array}$ & $\begin{array}{c}\text { BCG } \\
\text { coverage_NHFS4 }\end{array}$ & CFR & IMR \\
\hline Andhra Pradesh & 796919 & 6524 & 90.20 & 92.40 & 97.20 & 0.82 & 29 \\
\hline Arunachal Pradesh & 14077 & 32 & 54.20 & 57.70 & 70.90 & 0.23 & 37 \\
\hline Assam & 203282 & 896 & 53.50 & 62.40 & 82.30 & 0.44 & 41 \\
\hline Bihar & 209296 & 1026 & 37.70 & 64.70 & 91.60 & 0.49 & 32 \\
\hline Chandigarh & 13848 & 212 & NA & NA & 95.90 & 1.53 & 13 \\
\hline Chhattisgarh & 170130 & 1680 & NA & 84.60 & 98.40 & 0.99 & 41 \\
\hline Delhi & 344318 & 6163 & 92.00 & 87.00 & 95.00 & 1.79 & 13 \\
\hline Goa & 41586 & 564 & 99.20 & 96.80 & 100.00 & 1.36 & 7 \\
\hline Gujarat & 164121 & 3670 & 84.70 & 86.40 & 87.90 & 2.24 & 28 \\
\hline Haryana & 154495 & 1688 & 86.80 & 84.90 & 92.80 & 1.09 & 30 \\
\hline Himachal Pradesh & 19844 & 279 & 94.60 & 97.20 & 94.80 & 1.41 & 19 \\
\hline India & 7763067 & 117365 & 71.60 & 78.10 & 91.90 & 1.51 & 32 \\
\hline Jammu \& Kashmir & 90166 & 1412 & 85.60 & 90.90 & 95.60 & 1.57 & 22 \\
\hline Jharkhand & 98610 & 859 & NA & 72.70 & 95.80 & 0.87 & 30 \\
\hline Karnataka & 788551 & 10770 & 84.80 & 87.80 & 92.50 & 1.37 & 23 \\
\hline Kerala & 369324 & 1256 & 96.20 & 96.30 & 98.10 & 0.34 & 7 \\
\hline Madhya Pradesh & 164341 & 2842 & 64.90 & 80.50 & 91.60 & 1.73 & 48 \\
\hline Maharashtra & 1625197 & 42831 & 93.70 & 95.30 & 90.00 & 2.64 & 19 \\
\hline Manipur & 16621 & 127 & 71.00 & 80.00 & 91.20 & 0.76 & 11 \\
\hline Meghalaya & 8677 & 77 & 46.10 & 65.90 & 85.90 & 0.89 & 33 \\
\hline Mizoram & 2359 & 0 & 88.20 & 86.40 & 75.30 & 0.00 & 5 \\
\hline Nagaland & 8296 & 21 & 46.10 & 46.30 & 68.10 & 0.25 & 4 \\
\hline Odisha & 277887 & 1267 & 84.70 & 83.60 & 94.10 & 0.46 & 40 \\
\hline Puducherry & 33832 & 582 & NA & NA & 99.90 & 1.72 & 11 \\
\hline Punjab & 129693 & 4072 & 88.70 & 88.00 & 98.20 & 3.14 & 20 \\
\hline Rajasthan & 180755 & 1800 & 53.90 & 68.50 & 88.20 & 1.00 & 37 \\
\hline Sikkim & 3727 & 63 & 76.50 & 95.90 & 98.90 & 1.69 & 7 \\
\hline Tamil Nadu & 700193 & 10825 & 98.60 & 99.50 & 94.90 & 1.55 & 15 \\
\hline Telangana & 229001 & 1298 & NA & NA & 97.40 & 0.57 & 27 \\
\hline
\end{tabular}




\begin{tabular}{|c|c|c|c|c|c|c|c|}
\hline State/UT & $\begin{array}{l}\text { Case_22 } \\
20\end{array}$ & $\begin{array}{c}\text { Death_2 } \\
2 \_20\end{array}$ & $\begin{array}{c}\text { BCG } \\
\text { coverage_NFHS2 }\end{array}$ & $\begin{array}{c}\text { BCG } \\
\text { coverage_NFHS3 }\end{array}$ & $\begin{array}{c}\text { BCG } \\
\text { coverage_NHFS4 }\end{array}$ & CFR & IMR \\
\hline Tripura & 30067 & 336 & NA & 81.10 & 82.40 & 1.12 & 27 \\
\hline Uttar Pradesh & 463585 & 6790 & 57.50 & 61.00 & 87.60 & 1.46 & 43 \\
\hline Uttarakhand & 59508 & 968 & NA & 83.50 & 92.80 & 1.63 & 31 \\
\hline West Bengal & 337283 & 6308 & 76.50 & 90.10 & 97.50 & 1.87 & 22 \\
\hline
\end{tabular}

NA: Not available, IMR: Infant Mortality Rate, CFR: Case Fatality Rate, NFHS: National family health survey

TABLE 2 CORRELATION AND PARTIAL CORRELATION OF BCG COVERAGE WITH COVID-19 RELATED CASES, DEATHS AND CFR IN INDIA

\begin{tabular}{|c|c|c|c|c|c|c|}
\hline & $\begin{array}{l}\text { Correlation co- } \\
\text { efficient (NFHS2) }\end{array}$ & $\begin{array}{l}\text { Correlation co- } \\
\text { efficient (NFHS3) }\end{array}$ & $\begin{array}{l}\text { Correlation co- } \\
\text { efficient } \\
\text { (NFHS4) }\end{array}$ & $\begin{array}{l}* * \text { Correlation co- } \\
\text { efficient } \\
\text { (NFHS2) }\end{array}$ & $\begin{array}{l}{ }^{* *} \text { Correlation co- } \\
\text { efficient } \\
\text { (NFHS3) }\end{array}$ & $\begin{array}{l}{ }^{* *} \text { Correlation co- } \\
\text { efficient } \\
\text { (NFHS4) }\end{array}$ \\
\hline Cases & 0.032 & 0.030 & 0.048 & 0.109 & 0.077 & 0.059 \\
\hline Death & 0.061 & 0.058 & 0.035 & 0.127 & 0.096 & 0.042 \\
\hline CFR & $0.398^{*}$ & $0.468 *$ & $0.461^{*}$ & $0.444 *$ & 0.498* & $0.458^{*}$ \\
\hline
\end{tabular}

\section{Figures}

FIGURE 1 SCATTERED PLOT SHOWING THE RELATIONSHIP BETWEEN BCG COVERAGE (NFHS3) AND COVID-19 CFR IN INDIA

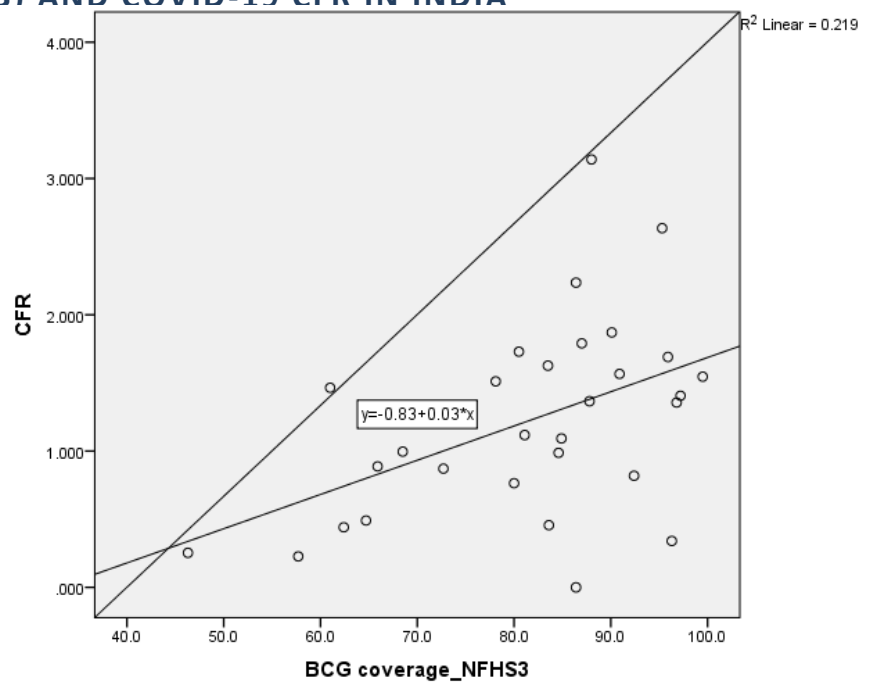

FIGURE 2 SCATTERED PLOT SHOWING THE RELATIONSHIP BETWEEN BCG COVERAGE (NFHS2) AND COVID-19 CFR IN INDIA

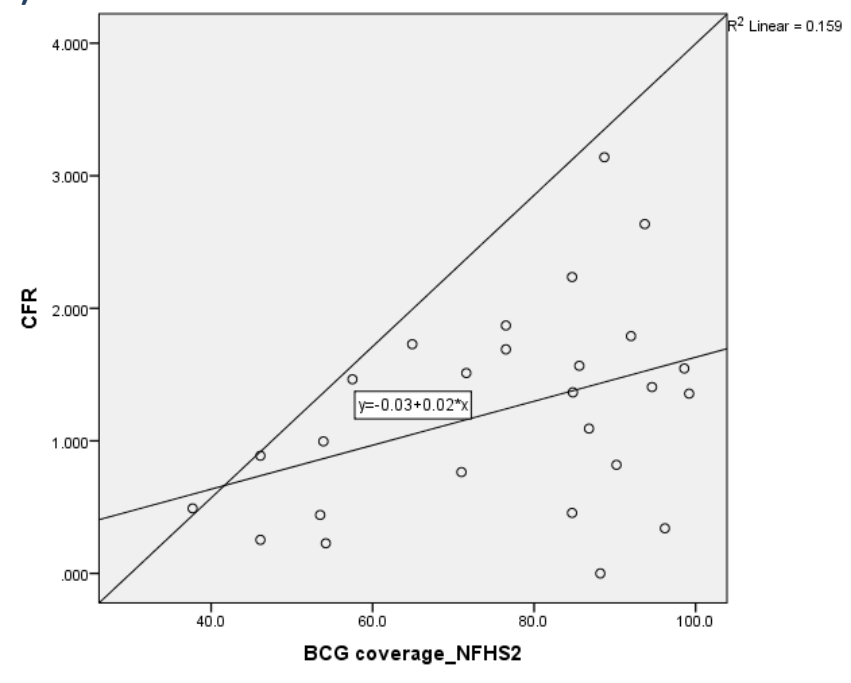

